\title{
Memory reconsolidation in psychotherapy for severe perfectionism within borderline personality
}

\author{
Alexandre $\mathrm{Vaz}^{1}$ (1) | Bruce Ecker ${ }^{2}$
}

${ }^{1}$ Clinical Psychology Department, ISPAUniversity Institute, Lisboa, Portugal

${ }^{2}$ Coherence Psychology Institute, Oakland, California, USA

\section{Correspondence}

Alexandre Vaz, Rua Barão de Sabrosa, $N^{\circ}$ 157, $3^{\circ}$ Direito, Lisboa 1900-088, Portugal. Email: alexmagvaz@gmail.com

\begin{abstract}
Objective(s): For a case of severe perfectionism, comorbid with complex trauma symptomatology including suicidality, self-harming, and other markers of borderline personality, we demonstrate the use of the empirically confirmed process identified in memory reconsolidation (MR) research for the unlearning and nullification, or "erasure," of emotional and behavioral responses driven by learned expectations and mental models. MR has been proposed as a transtheoretical, unifying mechanism underlying profound psychotherapeutic change. The therapist (first author), under the second author's supervision, used a varied set of clinical skills woven together through a focus on the MR process.
\end{abstract}

Results: The result was a depotentiation of underlying, traumatic emotional learnings and near-total disappearance of perfectionistic and self-harming behaviors, urges and attitudes after 1 year of therapy.

Conclusions: Implications of this case are discussed in terms of symptom generation by implicit emotional learnings and MR as a promising framework for advancing the effectiveness and unification of psychotherapy.

\section{KEYWORDS}

borderline personality, complex trauma, implicit emotional learning, mechanism of change, memory reconsolidation, perfectionism, psychotherapy 


\section{1 | INTRODUCTION}

Perfectionism has been conceptualized as a personality style characterized by setting of extreme standards for performance and striving for flawlessness (Stoeber, 2017). While perfectionism can have an adaptive role (Stoeber \& Otto, 2006), seriously problematic perfectionism is significantly associated with various forms of clinical symptomology (Limburg, Watson, Hagger, \& Egan, 2017). However, enhancing the effectiveness of psychological treatments for clinical perfectionism is limited by a lack of knowledge of the internal mechanisms of change (Kazdin, 2014). Memory reconsolidation (MR), an innate mechanism for changing memory contents that is well understood neurobiologically, has been proposed as a promising candidate mechanism of lasting psychotherapeutic change (Ecker, 2018; Ecker, Ticic, \& Hulley, 2012; Lane \& Nadel, 2020). The following sections address how compulsive perfectionism is based in memory and how it can be changed by a process of MR.

\section{1 | Perfectionism as an implicit emotional learning}

Memory science can inform our understanding and treatment of clinical symptomatology, including clinical perfectionism. Compulsive perfectionism can be conceptualized as an implicit emotional learning, that is, an acquired response arising from an emotionally valenced mental model or schema that formed nonverbally outside of awareness (Ecker, 2018; Ecker et al., 2012). An example of such a perfectionism-generating schema after becoming conscious, affectively felt, and verbalized is, "Any mistake reveals that I'm a worthless person who deserves the shaming and rejection I receive, so I've got to make no mistakes." Such schemas form in response to concrete experiences, often attachment-based experiences, and represent coherent though nonconscious attempts at adaptation to an environment that has inflicted suffering. Having learned to expect that making any mistake or doing anything displeasing to others brings certain sufferings (such as abandonment, physical beatings, behavioral withdrawal of love, or shameful condemnation for utter unworthiness), the individual also learns the tactical, self-protective solution of perfectionism to avoid the expected sufferings. This solution becomes consolidated into schematic memory structures that influence present-day functioning. For example, in the case presented below, the client, a college student, was severely sleep-deprived and fatigued because instead of sleeping, she usually stayed awake and studied to get top grades and thereby avoid being judged (yet again) as a disgusting, worthless failure by her mother. She was not aware that her behavior was driven by that purpose.

\section{2 | Therapeutic strategy for transformational change}

When the source and cause of clinical perfectionism is an emotional learning in the form of a mental model or schema, such as "Any mistake reveals that I'm a worthless person who deserves the shaming and rejection I receive, so I've got to make no mistakes," therapy would be highly effective if it results in that schema losing its compelling, subjective realness. Then the very basis of the behavioral urges of perfectionism would no longer exist.

No internal mechanism or process of true unlearning was empirically known until MR was discovered in the 1997-2000 period (reviewed by Riccio, Millin, \& Bogart, 2006). Numerous neuroscience studies of MR have shown full unlearning or "erasure," with disappearance of emotional reactivations and responses persisting effortlessly, that is, without any ongoing preventative procedures (e.g., Björkstrand et al., 2015). The same has been reported in many anecdotal clinical observations (e.g., Ecker et al., 2012). The next section describes how MR operates and how MR research findings translate into therapeutic methodology. 


\subsection{MR in clinical practice}

Increasingly recognized as an important phenomenon of psychotherapeutic change (Lane \& Nadel, 2020), MR is the brain's innate mechanism for allowing current experiences to revise or "update" existing contents of memory, changing both the neural encoding of the target memory and its expression into subjective experience and behavior (e.g., Clem \& Schiller, 2016).

Most important for the treatment of clinical perfectionism is MR's strongest effect, profound unlearning, which has been observed in both animal and human studies and which some neuroscientists have termed the "erasure" of the target emotional learning (e.g., Agren et al., 2012; Clem \& Huganir, 2010) because all behavioral, emotional and physiological expression of the target learning permanently cease to be evocable, and amygdala activation as detected by functional magnetic resonance imaging has also been observed to disappear (Agren et al., 2012).

Across all laboratory studies that have demonstrated erasure, the concrete procedures have been diverse, but in every case the procedure induced in the animal or human subjects the same well-defined set of experiences. (e.g., the subjective experience of surprise can be induced by myriad procedures.) That set of subjective experiences has been defined as the empirically confirmed process of erasure, or ECPE (Ecker, 2018). The ECPE consists of three experiences: target learning reactivation, discrepancy, and disconfirmation.

Target learning reactivation experience occurs by bringing to the subject's attention some salient component of the target learning's contents. The subjective state of target learning reactivation is a state of active expectancy, that is, expecting the world to behave as is known in and predicted by the mental model/schema that is the target learning. For the client in our example below, imagining going to bed at a normal time rather than studying far longer would reactivate her fearful expectation of her mother's look of disgust and words declaring her worthless. Reactivation includes experiencing the emotions, feelings, cognitions, somatic sensations, and behavioral urges characteristically generated by that particular schema.

Target learning discrepancy experience occurs when, during or soon after reactivation, the subject experiences some violation of expectation, that is, some direct perception of a difference between what is known and expected according to the target learning, and how the world actually is. For example, a perfectionistic client is guided to visualize, on a large video screen, the remembered scene where she is 5 years old and mother contemptuously tells her she is worthless because she made the mistake of forgetting to put away her toys. The therapist asks the adult client, who is viewing this scene, "What do you feel about this? Should this little girl, who is you, feel she is worthless because she didn't put away her toys?" The client, through tears, earnestly says, "No, no, she isn't worthless because of that mistake." In experiencing that contradictory knowledge concurrently with the reactivated target schema "I am worthless if I make any mistake," the subject's brain registers the critical experience of discrepancy (which memory researchers term prediction error or memory mismatch). In response, the neural encoding of the target learning undergoes a rapid transition: It changes on a timescale of about $1 \mathrm{~min}$ from a stable, "consolidated" state in long-term memory, to a destabilized, deconsolidated state, which lasts about $5 \mathrm{~h}$. During that "reconsolidation window" the encoding is receptive to revision by any relevant new learning. By $6 \mathrm{~h}$, the encoding has automatically restabilized and reconsolidated.

Target learning disconfirmation experience, created after the discrepancy experience unlocks the encoding, consists of a few repetitions of an experience that contradicts how the world is expected to be according to the target learning's model or schema. These counter-learning experiences during the reconsolidation window drive the disconfirmation and unlearning of the target schema and rewrite its neural encoding.

Following those experiences, the prompt, distinctive markers of successful erasure include: The target learning is no longer reactivated by cues and contexts that formerly did so; the subject no longer experiences the ego state of the target learning; behavioral and emotional responses produced by the target learning no longer occur; and those changes persist permanently and effortlessly.

For facilitating the ECPE consistently across many clients and problematic conditions, three preparatory steps are necessary, listed in Table 1 as A, B, and C. These steps put the therapist in possession of the knowledge that 
TABLE 1 The therapeutic reconsolidation process (Ecker et al., 2012)

\begin{tabular}{|c|c|}
\hline Preparation phase & $\begin{array}{l}\text { A. Symptom identification } \\
\text { B. Retrieval of symptom's underlying emotional learning } \\
\text { C. Identification of contradictory knowledge }\end{array}$ \\
\hline Erasure sequence (ECPE) & $\begin{array}{l}\text { 1. Reactivation of target learning/schema } \\
\text { 2. Discrepancy by activation of contradictory knowledge (first juxtaposition, } \\
\text { destabilizing target schema) } \\
\text { 3. Disconfirmation by repetitions of juxtaposition during remainder of session } \\
\text { (counter-learning and nullification of target schema) }\end{array}$ \\
\hline Verification phase & $\begin{array}{l}\text { V. Verification of target schema erasure } \\
\text { - Symptom cessation } \\
\text { - Nonreactivation of target schema } \\
\text { - Effortless permanence }\end{array}$ \\
\hline
\end{tabular}

allows immediate facilitation of the ECPE, Steps 1, 2, and 3 in Table 1. The final phase of the methodology, verification of erasure (Step V), then consists of actively testing for and confirming the three markers of erasure listed at the bottom of Table 1. That set of steps, $A B C-123-\mathrm{V}$, termed the therapeutic reconsolidation process (TRP), was proposed by Ecker et al. (2012) as being the optimally direct and efficient therapeutic application of the ECPE identified in laboratory MR studies. Adjunctive additional steps are necessary to address complications that often occur in psychotherapy, such as resistance or the presence in the target learning of intolerably intense material stemming from traumatic experiences (for examples of which, see Ecker et al., 2012).

Viewing MR/ECPE as a mechanism of psychotherapeutic change for the treatment of clinical perfectionism, what matters is not the particular techniques used, but whether that mechanism has been effectively activated in a way that will end symptom production (Kazdin, 2014).

\section{2 | CASE ILLUSTRATION}

The following case of extreme compulsive perfectionism illustrates the use of the TRP by an integrative therapist (first author), under the supervision of the second author. Our account of this case focuses on showing how the steps of the TRP were fulfilled. It is beyond the scope of this article to present all nuances of this case comprehensively.

\section{1 | Presenting problem and client description}

"Sofia" is a female college student in her early twenties, with no siblings and a history of complex trauma related to chronic physical and emotional abuse by her parents throughout childhood and beyond. A nearly constant symptom in her adult life was a persistent, tormenting anxiety over her current performance in college. She was regularly sleep-deprived due to studying compulsively for long periods. She viewed her academic performance as her "one chance to prove my worth." She suffered from bouts of severe anxiety in delivering any written assignment, college homework, or group presentation, fearing that she would not meet her own standards. This perfectionistic urge was responsible, in her view, for having had two panic attacks in the span of a particularly busy college month. At various points in her academic life, she paid a tutor to search for flaws in her writing assignments, only to finally fire him because "I couldn't find anyone with my standards to review my own work." She displayed severe workaholism, manifesting in her incessant urge to study for not only her present academic classes, but also 
those she expected to attend during the coming years. She would spend most weekends, holidays, and vacations studying in her room or at the college campus.

Significantly, Sofia did not express any desire or intention to reduce her anxiety-laden, perfectionistic, workaholic, and self-defeating behaviors, instead seeking further help in maximizing study effectiveness. She expressed anger and contempt toward the psychiatrist with whom she previously consulted because he tried to persuade her to study less and focus more on social relationships.

Her family environment was extremely punitive, invalidating and rejecting. She grew up with a feeling of dread, a lack of protection and control, and an image of herself as "useless" and "disgusting." Her mother repeatedly denigrated and shamed her throughout childhood and physically assaulted her since her early teens, on various occasions telling her she "would never amount to anything" and "I wish you were never born." Sofia had a history of sporadic self-mutilation behavior starting in early adolescence.

She came for psychotherapy after being hospitalized for a failed attempt at suicide by overdose using her mother's antidepressant medication. The suicide attempt was precipitated by the breakup of a romantic relationship, allegedly the result of Sofia's continuous mood swings, repeated angry outbursts at the boyfriend, and long isolation periods for studying for school exams. Other features relevant for assessment were her history of self-mutilation, persistent, severely negative self-image, frequent anger outbursts, and a pattern of unstable and intense interpersonal relationships. Criteria for borderline personality were met.

Sofia received a referral for psychotherapy from the hospital where she was treated following her attempted suicide. At intake, her total score on the CORE-OM measure was 106 out of 140, which was in the "severe" range. For instance, she responded "most or all the time" to risk-assessment items such as "I have thoughts of hurting myself." She presented as a major concern for therapy the fact that her depression and anxiety could compromise her academic future if unchecked.

\subsection{Course of treatment}

\subsection{1 | Initial phase: Creating safety and alliance, and identifying symptoms (TRP step A)}

Risk assessment and risk management necessarily took precedence initially. A therapeutic contract was set up in which the client agreed to not commit any self-harming behavior during the period of working together, and she was allowed to contact the therapist for emergency support. The first 3 months of weekly sessions were used for establishing relational rapport and alliance, identifying problems that the client wanted to address, and identifying possible causes and factors maintaining symptoms.

Sofia showed some awareness of the negative effects of her compulsive, extreme study habits, including sleep deprivation and marathon studying, and she described herself as a "failed perfectionist." Objectively, she excelled; her academic grades were higher than the grades of most of her fellow students. Regardless, she perceived any performance mistake or gap in knowledge as a sign of personal fault and a threat to her future. As she put it, "My mom always says, 'A mistake is two steps away from a failed life." It was already apparent that she carried emotional learnings defining any mistake as ruinous to personal worth and well-being.

Throughout the initial month of therapy sessions, Sofia felt highly ambivalent about psychotherapy and whether it could be of help. In Session 3, she stated that if the therapy made her less able to study, she would want to drop out. The therapist validated her desire for effective therapy, though without agreeing to her rigid terms and conditions. The following exchange illustrates how goal-setting was used to also make progress with symptom identification (TRP step A) while tactfully avoiding client resistance and alliance ruptures: 
1. T: It makes total sense to me that you'd want to study more effectively. Seems like having good grades could make a big difference in your life.

2. S: Yeah. I just can't afford to- It's too important.

3. T: Yeah, seems like you have really good reasons to want to study so hard. [Initial small step toward explicitly recognizing the existence of symptom-generating emotional learnings.]

4. S: And it's not like I don't have a personal life, okay? I have friends, I go out. But I get anxious if I stay out too long. I start thinking about all the things I should be doing, how much more productive-

5. T: Right, feels really- [Th notices $\mathrm{Cl}$ is averting eyes away from contact.] What are you feeling right now?

6. S: ...Are you going to convince me that it's not that important?

7. T: For you to study, to be productive?

8. S: Yeah.

9. $\mathrm{T}$ : Is that something you hear a lot?

10. S: Sometimes. My friend says that constantly. [Looks down.]

11. T: Hmm. And what do you feel when she says that, that your studying is not that important; that you should maybe do less of it?

12. S: It really pisses me off.

13. T: You get angry. Can you say more? I understand it must be-

14. S: People just don't get why I have to do this, and judge me as if I'm some sort of paranoid idiot for trying.

15. T: I really want to thank you right now, because you're saying something so important. And it's really important here for us as well. I imagine it would be pretty irritating if here I'd be trying to convince you to study less.

16. S: [Brief silence] Sure. [Expectant look]

17. T: I want to let you know that I'm actually only interested in working with you towards your goals, and helping you feel more effective in whatever seems important to you. How does that sound?

18. S: Yeah. Good. I think. [Still doubtful, but looks less tense]

19. T: So you're saying you want help with studying more effectively, because it is important. And your anxiety and other problems seem to be getting in the way of that. Is that right?

20. S: Yeah, it is. [Looks even less tense] I get so worried that sometimes I vomit... I get headaches...

21. T: Right, right. Great, it's so good that you notice those signs of anxiety.

22. S: It gets really bad sometimes.

23. T: I can imagine... So listen: I'm wondering if part of our work here could actually be aimed at helping you feel more effective, in studying as well as any other areas of your life you might want us to look at. Would you want us to help you with any aspect that seems to be keeping you less effective, so that we might help you with that? [Using client's own words to define treatment focus and goal]

24. S: Yes, please. [More energized]

25. T: So let's take a look at what, specifically, seems to be keeping you from feeling more effective.

26. S: Well, the worry and-I'm constantly tired. [Smiles] I know, from not sleeping.

These alliance-building exchanges, which occurred several times during the first few sessions, have particular importance for the ensuing therapeutic process, particularly the completion of TRP steps A and B, identification of symptoms and the conscious accessing of their underlying emotional learnings. If the therapist had focused unilaterally on defining the client's current behavior patterns as negative and undesirable, an alliance rupture would certainly have resulted, hindering progress and possibly ending therapy.

By continuously prizing the client's goals and personal agency, and empathizing with her underlying distress, enough headway was made to explore the possibility for less costly ways of ensuring academic and career success. While still feeling that her perfectionistic behaviors were necessary, Sofia began to express dislike of them. Specifically, she asked herself in session why she would engage in such counterproductive ways, often describing 
her behavior as "crazy," "irrational," and, in later sessions, "like something foreign, that I don't really agree with." For her to experience her own perfectionistic compulsivity as dystonic was a significant shift, made possible by her trust in the therapist's respect for her core purposes that her perfectionism was needed for achieving.

\subsection{2 | TRP step B: Retrieval of implicit emotional learnings}

The therapy work now moved into a concerted effort to make sense of her anxiety-ridden perfectionism instead of only finding how best to live with it and endure it. Sofia's interest in making sense of it made her receptive to a gently developing approach to TRP step B, in which the client discovers her own emotional learning(s) that indeed make deep sense of the symptom's existence. As noted earlier, an emotional learning underlying a given symptom is at core a mental model or schema, according to which the symptom is necessary to have in some in some adaptive, coherent way. Direct, affective experience of the schema brings direct experience of both a selfprotective purpose requiring the existence of the symptom and personal agency in producing the symptom (Ecker et al., 2012).

The process of bringing the underlying, symptom-requiring schema into direct awareness requires on the part of the therapist a radical acceptance of the emerging material just as it is, with no attempts to counteract, change or dispel it in any way whatsoever. With Sofia's consent and readiness to focus such work on her perfectionism, the therapy then proceeded to bring her attention into the implicit emotional learning within which her perfectionism was adaptively necessary. The therapist used a particular technique, symptom deprivation, designed specifically for this task of eliciting a symptom-requiring schema into direct experience. This technique invites the client to imaginally experience being without the symptom in a situation that would normally trigger it (Ecker \& Hulley, 1996; Ecker et al., 2012). The purpose is for the client to experientially contact the expected dreaded consequences that would result from living without the symptom, thus helping uncover the client's symptom-requiring schema. The following transcript begins immediately after Sofia had reported that after going out with a friend instead of staying home studying, she had felt panicky. Her panic is the symptom now being addressed, and symptom deprivation will be used to elicit the underlying source of that panic.

1. T: Can we actually go back and really find out what was going on for you then? Do you feel OK about doing an experiment?

2. S: Sure.

3. T: Could you close your eyes and try picturing yourself with this friend? Picture yourself going out, exactly like you did that time. It might help picturing specifics, like where you were, what you're doing. [Pause] You got it?

4. S: Yeah.

5. T: [Asks her to describe some details in the image, in order to help make the imaginal experience more vivid.]

6. S: [She describes a few details.] Now I'm getting restless.

7. T: If you can, stay with what's coming up. So, what's coming up for you right now?

8. S: [With eyes remaining closed.] Oh, I just think I shouldn't be here, I should be back home being productivelike, "What the hell is wrong with me?"... It's just this pressure. Now I can only think of all the work I need to do at home. ... [Anxiety is clearly developing, and going home to work is her only known way to reduce that anxiety.]

9. T: Okay. So, it's like, "I can't be enjoying myself here, I should be at home working."

10. S: Yeah.

11. T: Okay. You're doing great. Now, I'm gonna ask you to try something. See what you experience in this situation if you don't have this anxiety. Really let yourself imagine being there without this pressure. You're just there, relaxing, enjoying yourself, laughing. Carefree. [Th keeps describing the anxiety-free state, to guide her into more fully inhabiting it.]

12. S: [Spontaneously] I just have this image of my mother slapping me. 


\section{T: [Surprised] Wow!}

14. S: [Still with eyes closed, and now visibly tensing up] Yeah, I know, pretty stupid.

15. T: So stay with that. What's coming up in this image?

16. S: She's angry at me. She just showed up, where my friend was. [Pauses, tenses up] She's telling me I'm worthless, that she knew it all along. That I've settled for being a failure. And it's not even the slap that I hate. It's her face. She just has this horrible look on her face.

17. T: What's the look? Tell me.

18. S: It's like-[makes a facial expression] like disgust. [Tenses up]

19. T: Like somehow she's disgusted at you? Disgusted at your failing to live up to-?

20. S: Oh God, it's awful. [Cries] I can't take it.

21. T: Yeah, it's so painful to see it, that face feels unbearable. So tell her-can you try telling her, "Mom, I'm gonna try my best to not relax, to be perfect, so you won't feel disgusted at me"? Can you try saying something like that, whatever feels true to you? "Mom, I-".

22. S: [Crying] Mom, I'll stop. I'll behave. Please don't look at me like that. I'll be better. I'll try more.

The symptom deprivation exercise succeeded in revealing the specific suffering expected (nonconsciously) due to being without the symptom. Implicit knowledge of that suffering and of being vulnerable to that suffering is a major piece of the emotional learning underlying the symptom. The other major piece is the knowledge of how to avoid that suffering by producing the symptom. That is the revealed structure of symptom-generating emotional learnings, as a rule: knowledge of a suffering that is urgent to avoid (the problem), and knowledge of how to avoid it (the solution) (Ecker, 2018; Ecker et al., 2012).

When the underlying material had emerged in the symptom deprivation exercise, the therapist guided the client to make an overt statement of it: "Mom, I'm gonna try my best to not relax, to be perfect, so you won't feel disgusted at me." He also invited the client to change the words according to what feels true, and she did. Both techniques, symptom deprivation and overt statement, were developed for use in coherence therapy (Ecker \& Hulley, 2019), but they are versatile tools that can enhance experiential work in many therapeutic systems. The imaginal work in that session continued until the client felt safer and much less distressed, partly through reassuring her imagined mother that she would comply completely.

In the next sessions, there was an ongoing experiential exploration into the implicit emotional learnings driving Sofia's workaholism and perfectionism. This yielded some important findings, which again the therapist invited Sofia to express as overt statements, including these:

- To parents: "I'm trying to show you how much I love you by trying to not make any mistakes."

- To parents: "I'll stay locked up at home so you'll know that I care."

- To mother: "You might finally like me if you see me succeed."

- To mother: "I'd rather give up feeling good than seeing you look at me like that."

- To mother: "I won't relax, or I know you will think I've decided to just become a failure after all."

Those overt statements were usually accompanied by strong emotion, often with deep crying. The overt statement that Sofia finally felt was her most crucial emotional truth was this one to her mother: "I'm not going to relax, because I don't want you to hate me." With further experiential work, to that she added, "I'd rather keep trying for impossible perfection than you hating me." Also, Sofia commented more than once at this stage of her therapy that previously she had no awareness that her intense perfectionism was strongly linked to her mother.

That was good progress in carrying out TRP step B for Sofia's symptoms of anxiety, perfectionism, and workaholism. The emotional learnings generating those symptoms had been completely outside of awareness, but had now become well integrated into routine, daily awareness, not merely as cognitive insights but as richly felt emotional truths. These emotional learnings consisted of her knowledge of her parents' values and demands for 
nonstop, flawless work; her knowledge of their unbearably devaluing, denigrating responses when she does not fulfill their values and demands; and her belief about herself, received from her parents, that if she does not work constantly and perfectly, she is an utter failure and a disgusting, worthless person. It was also now apparent why she responded with anger and anxiety to attempts by friends, her ex-boyfriend, and her psychiatrist to interfere with her desperately needed perfectionism.

\subsection{3 | TRP step C: Finding contradictory knowledge}

With the content of the relevant emotional learnings well known from TRP step B, the work could now proceed to step C: identifying a contradictory knowledge. For this purpose, the therapist enquired with the client about any memory or experience that directly contradicted the specific implicit learnings sustaining her symptoms. This was not a simple or easy task. Sofia's autobiographical memories were riddled with stories of neglect and abuse, hindering attempts to find a specific memory from Sofia's life that powerfully disconfirmed any main features of the target learnings.

Since no contradictory knowledge was found in the client's past experiences, the task then became to actively create such a disconfirming experience in the present. This can be done in various ways (Ecker \& Hulley, 2019) utilizing daily life experiences, the client-therapist relationship, parts or ego-state work, or a structured revisiting of a past experience that contributed to learning the symptom-requiring schema, with the client now guided to perceive and experience the original situation in a new way that disconfirms the original learning.

The therapist chose a form of experiential parts and ego state work that uses two chairs, a technique that originated in psychodrama and became important also in Gestalt therapy, emotion-focused therapy, transactional analysis/redecision therapy, and schema therapy (reviewed by Kellogg, 2004). In these two-chair enactments, Sofia would start by voicing, in one chair, a part of herself that deeply felt and accepted as truth her original implicit emotional learnings. Then, sitting in the other chair, another part of her evaluated and reacted to what had been said, first by submitting to it, and later by recognizing and objecting to the untruth of it. After three sessions of this study, the client was experiencing two deeply felt knowings that contradicted her original emotional learnings:

- "Striving for perfection never actually got Mom to treat me better." This contradicts Sofia's fundamental belief and expectation that by behaving as Mom demands, she would arrive at having Mom's approval and acceptance, which is the hope and the need that is the very basis for her compliance, and without which compliance is pointless and senseless.

- "My friends, my ex-boyfriend, and my other family members like me more when I'm not trying to be perfect." This recognition contradicts Sofia's generalized expectation that everyone judges her as Mom does, and that without Mom's approval and acceptance, there is no other nurturing, sustaining connection, all is lost, and life is desolation.

With those fruits of TRP step $C$, the process could now advance from the preparation phase to the erasure sequence, TRP steps 1, 2, and 3 (the ECPE from MR research).

\subsection{4 | TRP steps 1, 2, and 3: The core process of transformational change}

During TRP step C, the therapist finds how to guide the client into an experience of knowings that are contradictory of the target emotional learning underlying the symptom. However, the target learning is not actually contradicted and disconfirmed, and unlearning does not occur, until the client experiences both at once, the target learning and the contradictory knowledge, in the same field of awareness, in juxtaposition. That juxtaposition experience is initially produced by TRP steps 1 and 2 , and is then repeated just a few more times in step 3 . 
Therefore, the task was now to guide Sofia to experience such juxtapositions involving the contradictory knowings listed above. The therapist guided her first to reconnect to her affectively felt experience of her deeplyheld original learning, verbalized to her mother as, "I mustn't allow myself to have a relaxed, pleasurable life, because I don't want you to hate me." With that emotional truth again affectively reactivated (Step 1), the therapist now gently invited her to also bring into awareness her vivid experience of the contradictory knowledges, verbalized as listed above (Step 2). Then, to make sure that the juxtaposition experience was actually occurring, the therapist asked, "How is it to be in touch with both of those, right now?" That simple question (Ecker et al., 2012) prompts the client into a mindful examination of the juxtaposition experience, which assures that the client is attending to the emotionally felt truth in both knowledges at the same time. Importantly, there was no favoring of either side expressed by the therapist. For Sofia, as for most clients, the juxtaposition experience was affectively intense in itself, including considerable surprise. She reacted to this first main juxtaposition experience by remarking repeatedly, "It just doesn't fit!", referring to the two juxtaposed emotional truths. The therapist then created a few repetitions of this juxtaposition experience during the rest of the session by simply continuing to review and ask about these two contrasting emotional truths with empathy and curiosity. These gentle invitations to repeatedly experience both truths fulfilled TRP step 3.

The ECPE-driven unlearning of a mental model is sometimes context-specific rather than global (Ecker, 2018; Ecker et al., 2012) and therefore has to be extended progressively to the various contexts in the client's life. During the next 6 months, in response to Sofia's reports of new emotional turmoil in response to new situations, it proved necessary to facilitate similar juxtaposition experiences in new contexts, again mainly using experiential chair work and imagery work. Considerable time was given to processing and integrating these experiences by discussing their immediate impact on her.

Following a juxtaposition experience in Session 23, Sofia said, "I'm honestly shocked at how I've always assumed that I had to be a certain way to get what I want. And it's even more shocking seeing that that's probably not right-that actually, I've been waiting for something good to happen, and maybe creating the conditions for that to never happen." This was later synthesized into a sticker note that she wrote and put up on a wall at home: "I don't want to earn a good life, I want a good life." These statements were indications of a significant degree of disconfirmation and unlearning of the mental model she had acquired from her parents, according to which her only possible way to have a good life was to earn it through continual, endless perfect performance.

At this stage, Sofia reported spontaneously and consciously breaking her perfectionistic patterns, and feeling much less anxious in doing so. She deliberately experimented with going out more with friends, sleeping longer hours, and tolerating not needing to know all her class materials in advance. While in the past a considerable part of her behavior was governed by what she thought she "should" do, her speech was now much more frequently focused on her wants and needs. She talked more actively about her personal interests, namely traveling and culinary, and expressed her wish to invest more time in these. She would describe small instances that evoked a great sense of empowerment and some surprise, such as joyfully planning a vacation abroad with friends, or watching internet videos to learn how to cook. While seemingly simple occurrences, the therapist was struck by how much these behaviors contrasted with her past workaholic standards, and specifically how her pride was now present in the consulting room, an emotion virtually nonexistent in her life at the beginning of treatment. None of these new behaviors had been suggested or assigned by the therapist. Additionally, Sofia reported that impulses and fantasies of self-harming, which had plagued her for many years, had completely disappeared.

Another moment that was later highlighted by the client as particularly important was a piece of disconfirmation work that occurred within the client-therapist relationship. In Session 43, the therapist disclosed feeling moved and proud of the client for her progress and efforts towards greater well-being. Listening to the therapist expressing these heartfelt feelings toward her, the client burst into tears. Upon inquiry, the client said she was genuinely surprised to recognize that she actually believes the therapist about his feeling moved by her and proud of her. This recognition, further explored, felt particularly meaningful and touching to her because receiving such regard from the therapist directly contradicted her implicit learnings that her genuine, imperfect, struggling 
self could never be admired and appreciated by any authority figure or person of standing, such as a therapist. Thus the therapist's disclosure of his sincere feelings toward the client had created yet another juxtaposition experience, one that further dissolved her emotional learnings of fundamental unworthiness.

\subsection{5 | Outcome and prognosis: Verification of transformational change (TRP step V)}

Sofia completed her year of therapy experiencing a near-total absence of her perfectionistic strivings. She was aware that she still carried considerable unprocessed grief and anger towards her parents, but felt satisfied and wanted to suspend therapy for the time being. She no longer experienced her symptom of "exploding anger" towards any of her friends and colleagues, but still had some angry outbursts towards her parents, though much less frequently than at the start of therapy. She no longer felt it necessary to deprive herself of sleep, fun, or social activities. Her grades continued to excel, although somewhat less so than before, but she said she felt okay about this. Her relaxed acceptance of any degree of lower academic grades was a very big change in her relationship to performance. She maintained her newfound commitment to enjoyable personal activities, namely investing in private cooking lessons and planning for future travel opportunities.

Regarding the criteria of the verification phase (Step V) in the TRP (Table 1), many of Sofia's original symptoms and their underlying implicit learnings seemed to no longer be reactivated in their original triggering contexts, such as going out with friends, studying for exams, relaxing, and ending the day at a sensible bedtime, and also talking with her mother. In the past, Sofia would feel severe anxiety and self-judgment after any confrontation with her mother, specifically whenever mother criticized Sofia's social and love life. By the end of therapy, Sofia felt angry at her mother's constant critical attitude and no longer believed or felt that her mother's critiques and insults were true indications of her personal worth. Instead, she looked for support in other relationships and expressed considerable anger and disgust for her mother's overall attitude of harsh denigration towards her throughout the years. This shift was in sharp contrast to Sofia's previously felt sense of shameful low self-worth and raw anxiety over seeing her mother's disapproving face.

The freedom from anxiety-laden self-judgment and perfectionism that she described was persisting without any conscious effort to maintain it or prevent relapse, as per TRP step V criteria. Shortly before therapy ended, Sofia reunited with her ex-boyfriend and was feeling happy in this relationship. At that point, her self-reported total score on the CORE-OM measure had decreased from the initial level of 106 down to 26 out of 140, which was now in the "low level" range.

\section{3 | CLINICAL PRACTICES AND SUMMARY}

What MR research potentially adds to the clinical landscape is the recognition of a fundamental mechanism and meta-process that could harmoniously coordinate the use of diverse therapeutic methods that for decades have appeared to be inherently foreign to each other and disjointed when combined in the same clinical case. For the treatment of clinical perfectionism, the MR/ECPE framework may provide coordination of diverse techniques, a well-defined process of change, and a focus on underlying causes.

In the present case study, the therapy outcome was a nearly total disappearance of perfectionism and anxiety symptoms. As noted, there were also a number of distinct indications from the client that underlying, symptomgenerating emotional schemas no longer felt real or true. At termination, Sofia's continuing anger at her parents differed in quality from the explosive outbursts that were no longer occurring, and appeared to be an appropriate, healthy response to her therapeutic recognition of her parents' mistreatment of her, even a marker of having largely shed her low self-esteem and self-blame. It is certainly possible that had she chosen to continue therapy with a focus on her anger and grief, additional schemas might have been found and unlearned, further freeing her. 
Research should address the hypothesis that the distinctive components of the MR/ECPE process are consistently detectable in cases where symptoms of clinical perfectionism are thoroughly or very largely eliminated, and consistently absent in cases of negligible to moderate levels of symptom reduction. Such studies could help confirm that the ECPE is the cause of profound unlearning of the emotional schemas at the core of clinical perfectionism.

\section{ACKNOWLEDGMENT}

Scientific editing by Giancarlo Dimaggio.

\section{ORCID}

Alexandre Vaz (DD https://orcid.org/0000-0001-8443-0064

\section{REFERENCES}

Agren, T., Engman, J., Frick, A., Björkstrand, J., Larsson, E. M., Furmark, T., \& Fredrikson, M. (2012). Disruption of reconsolidation erases a fear memory trace in the human amygdala. Science, 337, 1550-1552. https://doi.org/10. 1126/science.1223006

Björkstrand, J., Agren, T., Frick, A., Engman, J., Larsson, E. M., Furmark, T., \& Fredrikson, M. (2015). Disruption of memory reconsolidation erases a fear memory trace in the human amygdala: An 18-month follow-up. PLoS One, 10(7), e0129393.

Clem, R. L., \& Huganir, R. L. (2010). Calcium-permeable AMPA receptor dynamics mediate fear memory erasure. Science, 330(6007), 1108-1112.

Clem, R. L., \& Schiller, D. (2016). New learning and unlearning: Strangers or accomplices in threat memory attenuation? Trends in Neuroscience, 39(5), 340-351. https://doi.org/10.1016/j.tins.2016.03.003

Ecker, B., \& Hulley, L. (1996). Depth-oriented brief therapy: How to be brief when you were trained to be deep-and vice versa. Jossey-Bass.

Ecker, B. (2018). Clinical translation of memory reconsolidation research: Therapeutic methodology for transformational change by erasing implicit emotional learnings driving symptom production. International Journal of Neuropsychotherapy, 6(1), 1-92. https://doi.org/10.12744/ijnpt.2018.0001-0092

Ecker, B., \& Hulley, L. (2019). Coherence therapy practice manual and training guide (8th ed.). Oakland, CA: Coherence Psychology Institute.

Ecker, B., Ticic, R., \& Hulley, L. (2012). Unlocking the emotional brain: Eliminating symptoms at their roots using memory reconsolidation. New York, NY: Routledge.

Kazdin, A. E. (2014). Moderators, mediators, and mechanisms of change in psychotherapy. In W. Lutz, \& S. Knox (Eds.), Quantitative and qualitative methods in psychotherapy (pp. 87-101). East Sussex, UK: Routledge.

Kellogg, S. H. (2004). Dialogical encounters: Contemporary perspectives on "chairwork" in psychotherapy. Psychotherapy: Research, Theory, Practice, Training, 41, 310-320. https://doi.org/10.1037/0033-3204.41.3.310

Lane, R. D., \& Nadel, L. (Eds.). (2020). Neuroscience of enduring change: Implications for psychotherapy. New York, NY: Oxford University Press.

Limburg, K., Watson, H. J., Hagger, M. S., \& Egan, S. J. (2017). The relationship between perfectionism and psychopathology: A meta-analysis. Journal of Clinical Psychology, 73(10), 1301-1326.

Riccio, D. C., Millin, P. M., \& Bogart, A. R. (2006). Reconsolidation: A brief history, a retrieval view, and some recent issues. Learning \& Memory, 13, 536-544. https://doi.org/10.1101/Im.290706

Stoeber, J. (2017). The psychology of perfectionism: Theory, research, applications. New York, NY: Routledge.

Stoeber, J., \& Otto, K. (2006). Positive conceptions of perfectionism: Approaches, evidence, challenges. Personality and Social Psychology Review, 10(4), 295-319. https://doi.org/10.1207/s15327957pspr1004_2

How to cite this article: Vaz A, Ecker B. Memory reconsolidation in psychotherapy for severe perfectionism within borderline personality. J Clin Psychol. 2020;1-12. https://doi.org/10.1002/jclp.23058 